\title{
Effects of traditional Chinese medicine Xin-Ji-Er-Kang formula on 2K1C hypertensive rats: role of oxidative stress and endothelial dysfunction
}

Ting-ting $\mathrm{Yu}^{1+}$, Kun Guo ${ }^{1+}$, Han-chun Chen ${ }^{2+}$, Chao-zong Lan ${ }^{3}$, Jian Wang ${ }^{3}$, Ling-ling Huang ${ }^{1}$, Xing-hui Wang ${ }^{1}$, Zhen Zhang ${ }^{4^{*}}$ and Shan Gao ${ }^{1^{*}}$

\begin{abstract}
Background: XinJiErKang (XJEK), a Chinese herbal formula, is identified as an effective preparation to treat coronary heart disease and myocarditis. The aim of the study is to investigate the anti-hypertensive effects of XJEK by oral administration and also to find out whether the drug has any role in oxidative stress and vascular endothelial function.

Methods: Clipping of the renal artery resulted in gradual elevation of the systolic blood pressure (SBP) which reached a plateau after 4 weeks of surgery. Treatment of hypertensive rats $(20 \mathrm{mmHg}$ higher than basic systolic blood pressure) with XJEK (6, 12, $24 \mathrm{~g} / \mathrm{kg} /$ day) and fosinopril $(15 \mathrm{mg} / \mathrm{kg} /$ day) respectively by intragastric administration started 4 weeks after surgery and continued for 4 weeks. The sham-operated (Sh-Op) controls received drinking water. BP was monitored weekly using tail-cuff apparatus. At the end of $8 \mathrm{wk}$, left ventricular systolic pressure (LVSP), left ventricular end-diastolic pressure (LVEDP), rate of rise of left ventricular pressure $( \pm \mathrm{dp} / \mathrm{dtmax}$ ) were examined (PowerLab 8/30, AD Instruments, Australia). The myocardial hypertrophy index was expressed as heart weight/body weight (HW/BW), the histological changes were investigated by hematoxylin and eosin (HE) and Van Gieson (VG) stain. Endothelium-dependent relaxations due to acetylcholine were observed in isolated rat thoracic aortic ring preparation. Superoxide dismutase (SOD) activity, malondialdehyde (MDA) and nitric oxide (NO) content in serum, contents of hydroxyproline (Hyp) in the ventricular tissue were assayed by xanthin oxidase method, thiobarbituric acid (TBA) method, Griess method and alkaline hydrolysis method, respectively. Angiotensin II (Ang II) content in serum was detected by radioimmunoasssay method.
\end{abstract}

Results: XJEK therapy potently improved cardiac function, inhibited myocardial hypertrophy, improved cardiac pathology change, decreased the myocardial cross-section area (CSA), collagen volume fraction (CVF) and perivascular circumferential collagen area (PVCA), reduced the content of Hyp in the left ventricular tissue, inhibited the decrease of SOD activity and increase of MDA, Ang II content in serum. Moreover, treatment with XJEK improved endothelial dysfunction (ED) manifested by promoting endothelial-dependent vasodilation of thoracic aortic rings and enhancing the NO activity in serum.

Conclusions: These findings suggest that administration of XJEK possess protective effects against 2K1C induced hypertension and cardiac remodeling in rats, preserve $\mathrm{NO}$ activity and endothelial function.

Keywords: Oxidative stress, Endothelial dysfunction, Antioxidant, Renovascular, Hypertension, Cardiac remodeling

\footnotetext{
*Correspondence: zhz36@sina.com.cn; aydgs@126.com

${ }^{\dagger}$ Equal contributors

${ }^{4}$ Department of General Surgery, the First Affiliated Hospital of Anhui Medical

University, Hefei, Anhui 230022, China

'Department of Pharmacology, Key Laboratory of Antiinflammatory and

Immunopharmacology of Education Ministry, Basic Medical College, Anhui

Medical University, Hefei 230032, China

Full list of author information is available at the end of the article
} 


\section{Background}

Human hypertension is usually a slowly-developing disorder from middle to old age. Hypertension is not only manifested by an increased arterial pressure, it also involves the complex structural and functional alterations of its target organs. Long-term hypertension often results in left ventricular hypertrophy, which is considered to be a risk factor for coronary heart disease, congestive heart failure (CHF), ventricular arrhythmia, and sudden death [1], as well as structural alteration of the vascular wall, which is manifested by endothelial dysfunction (ED), extracellular matrix deposition and medial layer thickening because of hypertrophy/hyperplasia and migration of vascular smooth muscle cells (VSMCs). Epidemiological data revealed that hypertension is responsible for $54 \%$ of stroke, $47 \%$ of ischemic heart disease, and $25 \%$ of other cardiovascular diseases worldwide; a total of 6.7 million deaths throughout the world ( $\approx 13.5 \%$ of all) are ascribed to high blood pressure [2]. On the other hand, chronic kidney artery diseases, such as renal artery stenosis, generally lead to hypertension, and one of the kidney related animal models of hypertension is 2-kidney, 1-clip (2K1C) model in which one of the renal arteries is subjected to partial stenosis by clip placement. Kidney ischemia results in increase in plasma renin and angiotensin activity [3] which in turn leads to persistent increase in blood pressure. In experimental renovascular hypertension, increased oxidative stress (OS) plays an important part in the pathogenesis of renovascular hypertension and the enhancement of the oxidation-sensitive signaling pathway [4]. Previous studies have reported that angiotensin II (Ang II) stimulates the production of reactive oxygen species (ROS) such as superoxide through the activation of membrane-bound NADH or NADPH oxidase [5,6]. Recently, ED is known to play important roles in the pathogenesis and progressiveness of hypertensive heart disease [7]. One of the key factors in ED is the overproduction of ROS which participates in the development of hypertension, atherosclerosis, diabetes, cardiac hypertrophy, heart failure, ischemia-reperfusion injury, and stroke [8].

Xin-Ji-Er-Kang (XJEK) is a topical Chinese herbal medicine (CHM) compound made from fourteen herbal medicines such as Panax ginseng, Astragalus mongholicus Bunge, Ophiopogon japonicus, Polygonatum odoratum and so on. Both clinical study and basic research have exhibited the curative effect of XJEK on hypertension induced coronary heart disease, virus myocarditis and toxic myocarditis $[9,10]$. XJEK has also been shown to exert protective effects against isoproterenol-induced ventricular remodeling in mice, which may be related to its actions in reducing the oxidative stress and improving the antioxidant activity of the body [11]. Our preliminary experiment results also demonstrated that XJEK prevented heart, kidney, vascular remodeling and injury in $2 \mathrm{~K} 1 \mathrm{C}$ induced hypertension rats [12].

The aims of this research, therefore, are to reveal whether XJEK can prevent 2K1C-induced hypertension and cardiovascular remodeling (CR) and, if so, to determine the underlying mechanism, focusing on the involvement of OS and ED.

\section{Methods}

\section{Preparation of XJEK extract}

$\mathrm{XJEK}$ consists of fourteen medicinal compositions as shown in Table 1. All of these herbs were purchased from Hefei Company of Traditional Crude Drugs (Hefei, China), and carefully authenticated by Dr. He-ping Huang (AnHui College of Traditional Chinese Medicine, HeFei, China). Voucher specimens (numbers were listed in Table 1) were deposited at the Herbarium of Nanjing University of Traditional Chinese Medicine (Nanjing, China). After drying, these plant materials were mixed in proportion and were macerated for $1 \mathrm{~h}$ at room temperature with eight times $(\mathrm{v} / \mathrm{w})$ distilled water. Then the whole mixture was decocted twice for $1 \mathrm{~h}$ each time. The filtrates were mixed and condensed and then dried by vacuum-drier at $60^{\circ} \mathrm{C}$. The yield of XJEK extract was $25.6 \%(w / w)$ according to the original herbs. The resulting powder, stored at $-20^{\circ} \mathrm{C}$, was diluted to the concentrations needed with distilled water and filtered before use.

\section{Animals and treatment}

Fifty-four male Wistar rats $(200 \pm 10 \mathrm{~g})$ were purchased from the Laboratory Animal Center of Nanjing Medical University. All procedures were performed in accordance with the protocol outlined in the Guide for the Care and Use of Laboratory Animals published by the US National Institute of Health (NIH publication no. 85-23, revised 1996) and approved by the Committee on the Ethics of Animal Experiments of An'hui Medical University. The animals were housed under standardized conditions, $12 \mathrm{~h}$ dark-light cycle in solid bottomed polypropylene cages, and received commercial rat chow ad libitum.

2K1C hypertension was induced by subjecting the animals to right renal artery clamping using a $0.25 \mathrm{~mm}$ silver clip under pentobarbital anesthesia. The animals were randomly assigned to one of six groups. 1: Shamoperated (Sh-Op) rats underwent the same surgical procedure, except for the placement of the renal artery clip. 2: Experimentally induced hypertensive model group that underwent right renal artery clamping $(2 \mathrm{~K} 1 \mathrm{C})$ and received tap water; 3: XJEK low dose group: Rats underwent $2 \mathrm{~K} 1 \mathrm{C}$ and received XJEK at $6 \mathrm{~g} / \mathrm{kg} /$ day; 4 : XJEK middle dose group: Rats underwent $2 \mathrm{~K} 1 \mathrm{C}$ and received XJEK at $12 \mathrm{~g} / \mathrm{kg} /$ day; 5: XJEK high dose group: Rats underwent $2 \mathrm{~K} 1 \mathrm{C}$ and received XJEK at $24 \mathrm{~g} / \mathrm{kg} /$ day; 6: Fosinopril group: Rats underwent $2 \mathrm{~K} 1 \mathrm{C}$ and received fosinopril at 
Table 1 Recipe of XJEK formulation

\begin{tabular}{|c|c|c|c|}
\hline Components & Voucher specimens number & Part used & Rate (\%) \\
\hline Panax ginseng C.A. Mey. & NJUTCM-20110530 & Root & 11.71 \\
\hline Polygonatum odoratum (Mill.) Druce & NJUTCM-20110531 & Rhizome & 7.03 \\
\hline Panax pseudoginseng var. notoginseng (Burkill) G. Hoo \& C.L. Tseng & NJUTCM-20110532 & Root & 3.09 \\
\hline Allium macrostemon Bunge & NJUTCM-20110533 & Ramulus & 7.80 \\
\hline Angelica sinensis (Oliv.) Diels & NJUTCM-20110534 & Root & 7.80 \\
\hline Ophiopogon japonicus (Thunb.) Ker Gawl. & NJUTCM-20110535 & Root & 7.80 \\
\hline Schisandra chinensis (Turcz.) Baill. & NJUTCM-20110536 & Fruit & 3.93 \\
\hline Salvia miltiorrhiza f. alba C.Y. Wu \& H.W. Li & NJUTCM-20110537 & Root & 7.80 \\
\hline Sophora flavescens Aiton & NJUTCM-20110538 & Root & 7.80 \\
\hline Glycyrrhiza acanthocarpa (Lindl.) J.M. Black & NJUTCM-20110539 & Rhizome & 7.80 \\
\hline Astragalus mongholicus Bunge & NJUTCM-20110540 & Root & 11.69 \\
\hline Epimedium acuminatum Franch. & NJUTCM-20110541 & Aerial part & 7.80 \\
\hline Trichosanthes obtusiloba C.Y. Wu & NJUTCM-20110542 & Seed & 7.80 \\
\hline Dryobalanops aromatica C.F. Gaertn. & NJUTCM-20110543 & Resin & 0.15 \\
\hline
\end{tabular}

$15 \mathrm{mg} / \mathrm{kg} /$ day. Treatment with XJEK was started 4 weeks after $2 \mathrm{~K} 1 \mathrm{C}$ hypertension was induced and maintained for an additional 4 weeks. Body-weight (BW) and tail systolic blood pressure (SBP) were assessed weekly throughout the experimental period.

\section{Measurement of systolic blood pressure}

SBP was measured in all groups using the tail-cuff apparatus (ALC-NIBP, Shanghai Alcott Biotech CO., LTD.) at weekly intervals. Before the measurements, the rats were warmed for $30 \mathrm{~min}$ at $28^{\circ} \mathrm{C}$ in order to allow the detection of tail artery pulsations and to achieve a steady pulse level. SBP was obtained by averaging 10 measurements.

\section{Haemodynamics and cardiac remodeling index}

At the end of eight weeks, all animals were anaesthetized with pentobarbital ( $45 \mathrm{mg} / \mathrm{kg}$, intraperitoneal injection), the right carotid artery was cannulated with a polyethylene catheter connected to a Statham transducer and then the catheter was inserted along the right coronary artery into the left ventricle, and the signals were recorded on a PowerLab 8/30 (AD Instruments, Australia) and digitally sampled $(1 \mathrm{kHz})$ on a personal computer using a chart software (version 5.3). The left ventricular systolic pressure (LVSP), left ventricular end-diastolic pressure (LVEDP) and rate of rise of left ventricular pressure $( \pm \mathrm{dp} / \mathrm{dtmax})$ were recorded.

Thereafter, blood samples were collected and centrifuged for $10 \mathrm{~min}$ at $3000 \mathrm{rpm}$, and all samples were stored at $-80^{\circ} \mathrm{C}$ for further use. Then the animals were killed by exsanguinations, and the thoracic cavity was opened to expose the still beating heart. The hearts were rapidly removed, rinsed in ice-cold $0.9 \% \mathrm{NaCl}$ solution, blotted and weighed. The heart-weight index $(\mathrm{HW} / \mathrm{BW})$ was calculated by dividing the heart weight by the body weight.

\section{Measurement of plasma Ang II levels}

Blood from the abdominal aorta was collected into a chilled glass tube containing protease inhibitors and Enalapril to inhibit ex vivo conversion of Ang I to Ang II (Sigma, St. Louis, MO). After elution from the column with $90 \%$ methanol, samples were dried and reconstituted for radioimmunoassay (RIA). The RIA for Ang II was performed using ${ }^{125}$ I-angiotensin II (Perkin-Elmer, Foster City, CA) and rabbit anti-Ang II antibody (Phoenix Pharmaceuticals, Inc., Belmont, CA) with cross-reactivity of $<2 \%$ for Ang II precursors and degradation products. After incubation for $48 \mathrm{~h}$ at $4^{\circ} \mathrm{C}$, bound and free Ang II was separated with dextran-coated charcoal. The supernatant was counted with a gamma-counter (ICN, Costa Mesa, CA). The ratio $\mathrm{B} / \mathrm{B}_{\mathrm{o}}$ was corrected for non-specific binding, expressed as a percentage of maximal binding, and read against a standard curve (log-logit transformation).

\section{Histological and morphological analyses of the heart and thoracic aorta}

After weighing the heart, $70 \%$ of the upper hearts were frozen in liquid nitrogen for measuring the contents of hydroxyproline, and the other 30\% were fixed in $10 \%$ formalin for histological analysis. Briefly, paraffin sections $(5 \mu \mathrm{m})$ were cut and stained with hematoxylin and eosin (HE) and Van Gieson (VG). Thereafter, the myocyte cross-sectional area (CSA), perivscular collagen area (PVCA) and collagen volume fraction (CVF) were quantitatively analysed with NIH Image 1.61 software (National Institutes of Health Service Branch) in digitalized microscopic images as has been previously described [13]. 
Thoracic aortas were removed from rats and cleaned before use, and then tissues were cleaned and fixed in formaldehyde. Paraffin-embedded thoracic aorta $(5 \mu \mathrm{m})$ was cut, dewaxed and stained with HE. The structural changes of aorta were investigated using a light microscope. Area of total aorta (TAA), area of lumen (LA), CSA, aorta radius (AR), luminal radius (L), and media thickness $(\mathrm{M})$ of aorta were recorded under a light microscope, and the ratio of $\mathrm{M} / \mathrm{L}$ was calculated as has been previously reported [13].

\section{Isolated vascular ring experiments}

Isolated vascular ring experiments were performed as we previously described [14], with minor modification. In brief, four-millimeter ring segments of the descending thoracic aorta were dissected and mounted in individual organ chambers filled with Krebs buffer (composition in $\mathrm{mM}$ ): $\mathrm{NaCl} 118, \mathrm{KCl} 4.75, \mathrm{NaHCO}_{3} 25, \mathrm{MgSO}_{4} 1.2$, $\mathrm{CaCl}_{2} 2, \mathrm{KH}_{2} \mathrm{PO}_{4}$ 1.2, glucose 11. The solution was continuously gassed with a $95 \% \mathrm{O}_{2}$ and $5 \% \mathrm{CO}_{2}$ mixture and maintained at $37^{\circ} \mathrm{C}$. Rings were stretched to $0.5 \mathrm{~g}$ of resting tension by means of two L-shaped stainless steel wires, which were inserted into the lumen and attached to the chamber and to an isometric forcedisplacement transducer. Rings were equilibrated for 60 to $90 \mathrm{~min}$, during which, tissues were restretched and washed every $30 \mathrm{~min}$ with warm Krebs solution. The concentration-relaxation response curves to acetylcholine $\left(10^{-8}-10^{-4} \mathrm{~mol} / \mathrm{L}\right)$ were performed in intact rings precontracted by $10^{-4} \mathrm{~mol} / \mathrm{L}$ phenylephrine. Relaxant responses to acetylcholine were expressed as a percentage of precontract induced by phenylephrine.

\section{Measurement of nitric oxide (NO), total superoxide dismutase (SOD) activities, malondialdehyde (MDA) content in serum and hydroxyproline (Hyp) content in cardiac tissue}

The methods of measuring NO have been described previously [15]. Because of its instability in physiological solutions, most of the $\mathrm{NO}$ was rapidly converted to nitrite $\left(\mathrm{NO}_{2}^{-}\right)$and further to nitrate $\left(\mathrm{NO}_{3}^{-}\right)$. Serum levels of $\mathrm{NO}_{2}^{-} / \mathrm{NO}_{3}^{-}$were measured using $\mathrm{NO}$ Detection Kit according to the manufacturer's instruction. Briefly, nitrate was converted to nitrite with aspergillus nitrite reductase, and the total nitrite was measured with the Griess reagent. The absorbance was determined at $540 \mathrm{~nm}$ with a spectrophotometer.

As has been described previously [16], MDA content was measured using thiobarbituric acid reactive substances (TBARS) assay following the manufacturer's instruction (Jiancheng Institute of Bioengineering Company, Nanjing, China) by measuring the absorbance value at wavelength of $532 \mathrm{~nm}$. SOD activity was measured using xanthine oxidase method to measure the absorbance value at $550 \mathrm{~nm}$ with SOD kit (Jiancheng Bioengineering, Nanjing, China).

The contents of Hyp in cardiac muscle were measured as described formerly [13] according to the explanations provided by the manufacturer.

\section{Statistical analysis}

All data are expressed as mean \pm SD. For all the statistical tests, multiple comparisons were performed by one-way ANOVA with Tukey-Kramer exact probability test. The least-squares method was used for linear correlation between selected variables. Statistical significance was accepted at $\mathrm{P}<0.05$.

\section{Results}

\section{Effect of XJEK on SBP}

SBP was considerably lower in the XJEK and fosinopril treated hypertensive rats as compared to experimentally induced hypertensive model group. A progressive reduction in BP was observed in XJEK and fosinopril treated groups from 5 week $(\mathrm{P}<0.05, \mathrm{P}<0.01$; Figure 1$)$. At the end of 8 weeks, experiment animals treated with XJEK (each dose) and fosinopril demonstrated reduced SBP significantly, which was near to the SBP of Sh-Op group rats.

\section{Effect of XJEK on haemodynamic parameters}

The measurements of in vivo left ventricular function for all groups were measured 8 weeks after $2 \mathrm{~K} 1 \mathrm{C}$. As shown in Table 2, systolic cardiac parameters, including LVSP, LVEDP, $+\mathrm{dp} / \mathrm{dt}_{\max }$, and diastolic cardiac parameter $-\mathrm{dp} /$ $\mathrm{dt}_{\max }$, were all significantly elevated in model group rats. These changes could also be prevented by treatment with

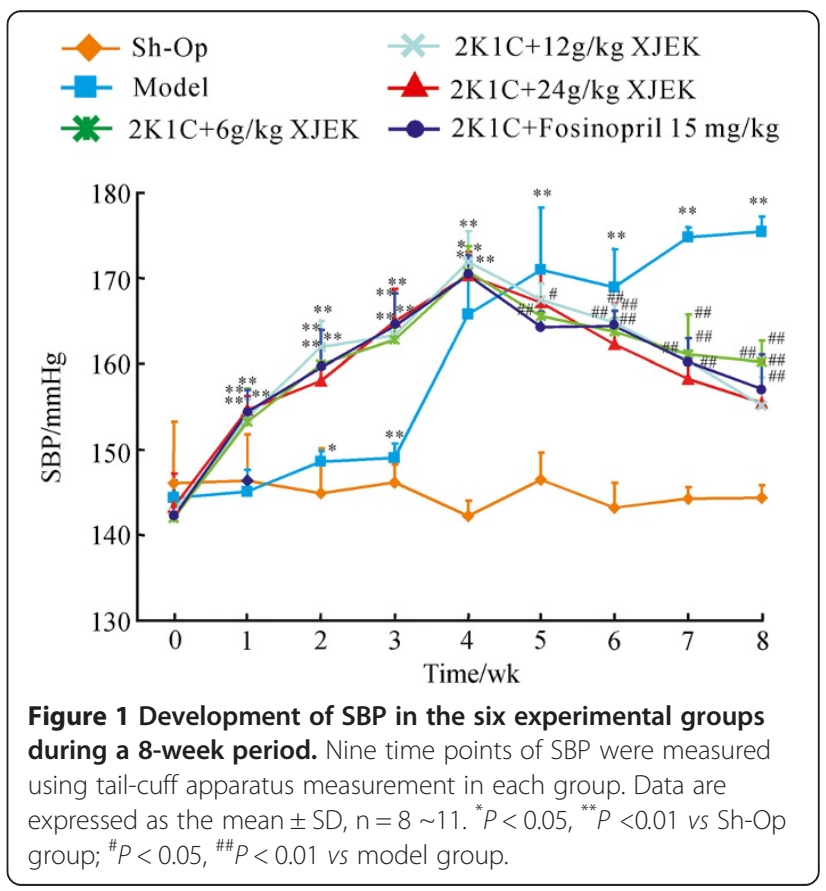


Table 2 Effects of XJEK on cardiac function in $2 \mathrm{~K} 1 \mathrm{C}$ hypertensive rats (mean $\pm S D, n=8 \sim 11$ )

\begin{tabular}{|c|c|c|c|c|}
\hline Group & LVSP $(\mathrm{mmHg})$ & LVEDP $(\mathrm{mmHg})$ & $+\mathrm{dP} \mathrm{dt}_{\max }(\mathrm{mmHg} / \mathrm{s})$ & $-\mathrm{dP} / \mathrm{dt}_{\max }(\mathrm{mmHg} / \mathrm{s})$ \\
\hline Sh-Op & $113.07 \pm 11.66$ & $27.56 \pm 9.11$ & $7672.57 \pm 2158.28$ & $-7046.04 \pm 1501.92$ \\
\hline Model & $149.21 \pm 20.68^{* *}$ & $46.93 \pm 19.92^{* *}$ & $8477.46 \pm 1123.74$ & $-7483.98 \pm 1122.43$ \\
\hline \multicolumn{5}{|l|}{ XJEK } \\
\hline $6 \mathrm{~g} / \mathrm{kg}$ & $121.34 \pm 16.99^{\# \#}$ & $40.88 \pm 7.40$ & $7358.72 \pm 1389.27$ & $-7679.91 \pm 1906.72$ \\
\hline $12 \mathrm{~g} / \mathrm{kg}$ & $115.61 \pm 14.16^{\# \#}$ & $35.66 \pm 9.49$ & $7140.11 \pm 2493.83$ & $-7666.94 \pm 1235.32$ \\
\hline $24 \mathrm{~g} / \mathrm{kg}$ & $113.60 \pm 15.86^{\# \#}$ & $37.93 \pm 4.28$ & $6310.59 \pm 1588.00^{\# \#}$ & $-7015.20 \pm 1162.04$ \\
\hline \multicolumn{5}{|l|}{ Fosinopril } \\
\hline $15 \mathrm{mg} / \mathrm{kg}$ & $110.53 \pm 11.26^{\# \#}$ & $36.65 \pm 12.28$ & $6514.32 \pm 2417.83^{\#}$ & $-7152.12 \pm 1789.97$ \\
\hline
\end{tabular}

LVSP left ventricular systolic pressure, LVEDP left ventricular end-diastolic pressure, $+d p / d t_{\max }$ maximal rate of left ventricular systolic pressure, $-d p / d t m a x$ maximal rate of left ventricular diastolic pressure. ${ }^{* *} P<0.01$ vs Sh-Op group; ${ }^{\#} P<0.05$, ${ }^{\# \#} P<0.01$ vs model group.

XJEK in a dose-dependent manner. The same results were observed in positive drug-fosinopril treated group.

\section{Effect of XJEK on cardiac remodeling in $2 \mathrm{~K} 1 \mathrm{C}$ rats} Histology of the hearts from the experimentally induced hypertensive model group rats showed that myocyte CSA, and levels of CVF, PVCA increased significantly $\left({ }^{*} P<0.01\right)$ as compared with those of the Sh-Op group (Figure 2-A,B, $\mathrm{D}$ and Figure 3-A,B,C,D). Morphological hypertrophy of heart was characterized by an increase in HW/BW ratios, which boosted significantly $\left({ }^{* * *} P<0.01\right)$ compared with those of the Sh-Op group (Figure 2-C), whereas the

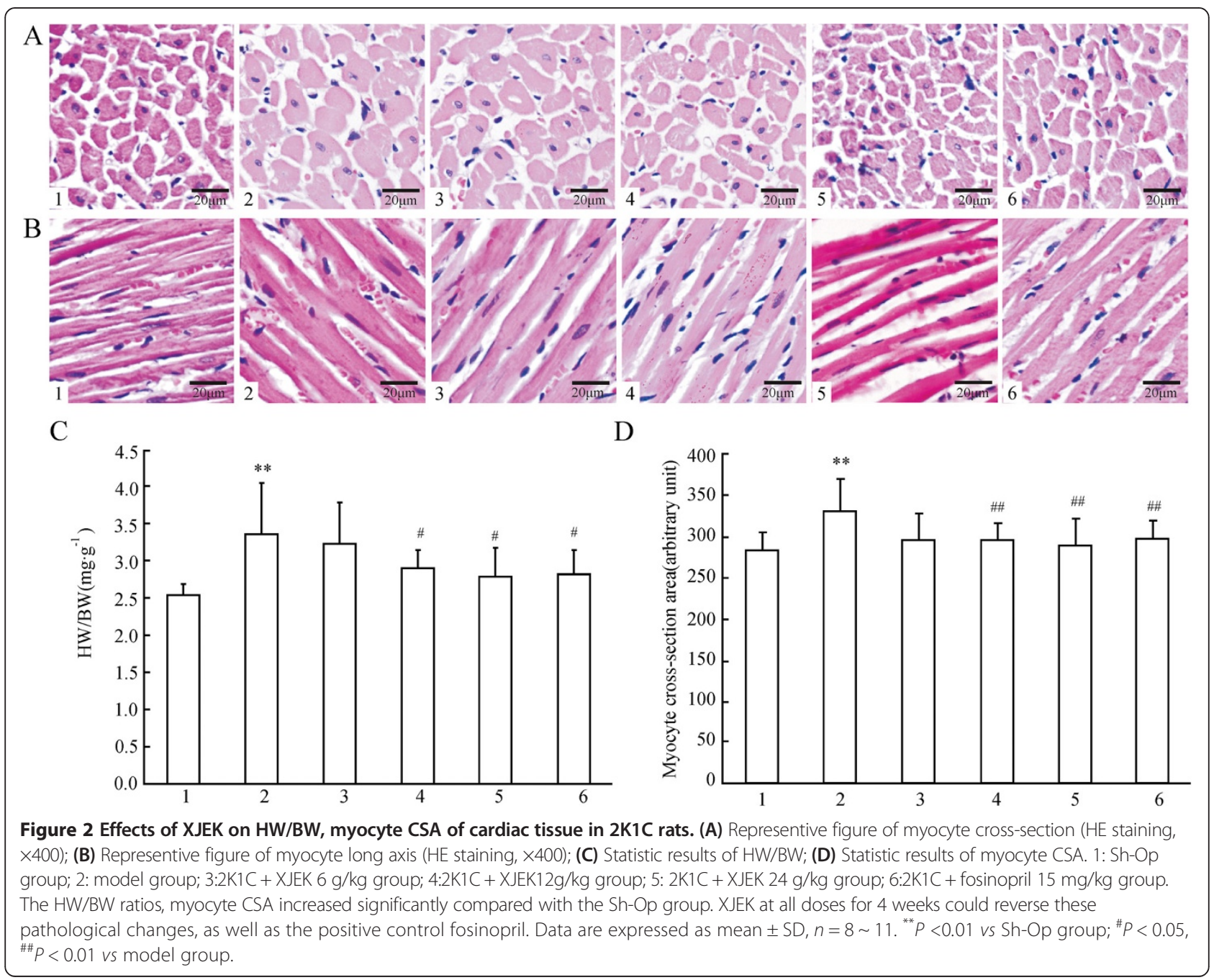




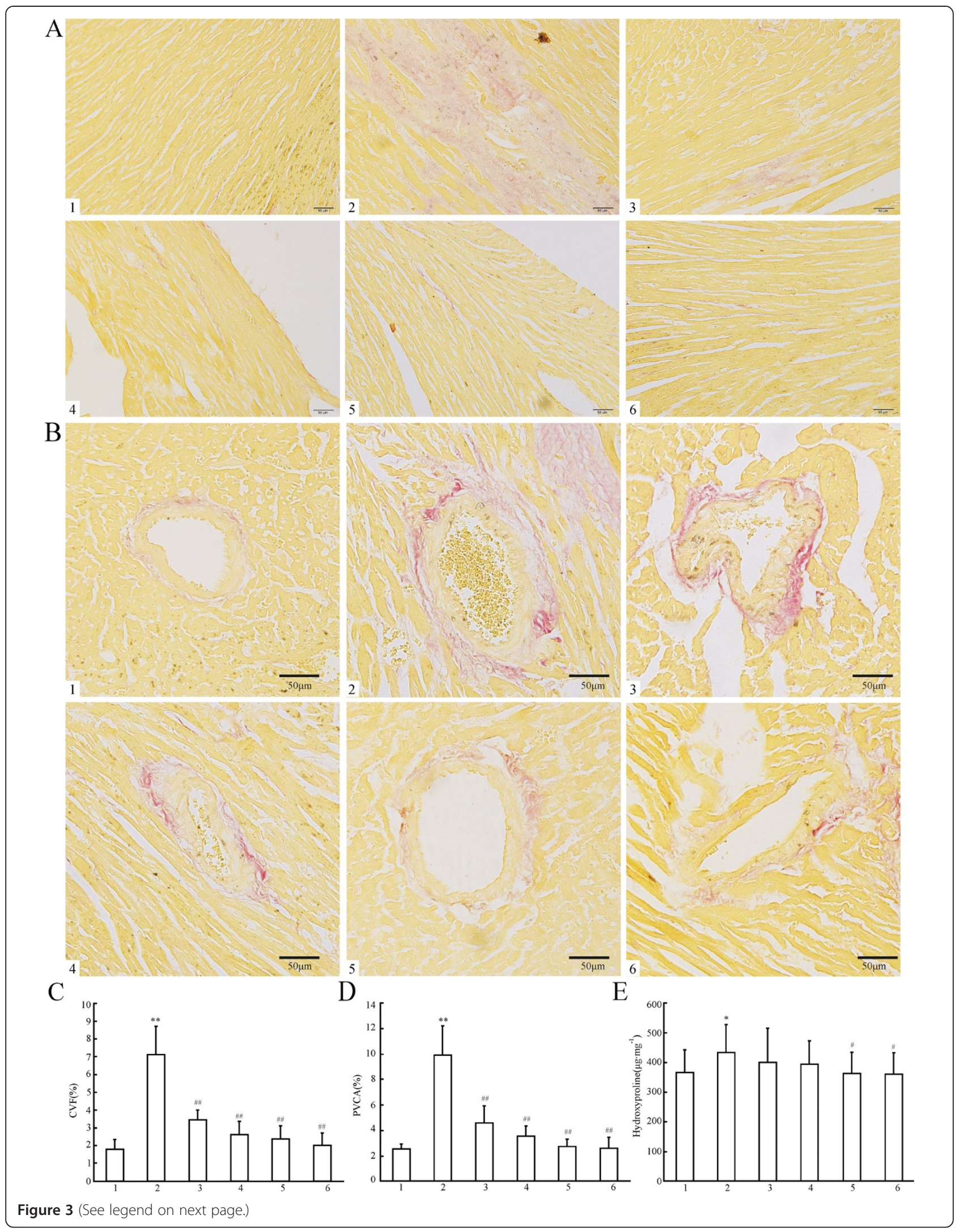


(See figure on previous page.)

Figure 3 Effects of XJEK on myocardial fibrosis, perivascular fibrosis, and cardiac Hyp content in 2K1C rats. (A) Representive figure of myocardial fibrosis (VG staining, $\times 400$ ); (B) Representive figure of perivascular fibrosis (VG staining, $\times 400$ ); (C) Statistic results of myocardial fibrosis; (D) Statistic results of perivascular fibrosis; (E) Statistic results of cardiac Hyp content in cardiac tissue. Group divided ibidem. Levels of myocardial and perivascular fibrosis, and the cardiac Hyp content all increased significantly compared with the Sh-Op group. XJEK at all doses for 4 weeks could reverse these pathological changes, as well as the positive control fosinopril. Data are expressed as mean \pm SD, $n=8 \sim 11$. ${ }^{*} P<0.05$, ${ }^{* *} P<0.01$ vs Sh-Op group; ${ }^{\#} P<0.05,{ }^{\# \#} P<0.01$ vs model group.

BW showed no significant difference among the groups (data not shown). Moreover, the hydroxyproline content reflecting the collagen level in cardiac tissue and the extent of myocardial fibrosis increased by $17.86 \%$ in experimentally induced hypertensive model group rats as compared with that of the Sh-Op group (Figure 3-E). XJEK at all doses for 4 weeks could reverse those pathological changes, as well as positive drug-fosinopril.

\section{Effect of XJEK on aortic remodeling in $2 \mathrm{~K} 1 \mathrm{C}$ rats}

The vascular remodeling of the upper thoracic aorta exposed to $2 \mathrm{~K} 1 \mathrm{C}$ rats was observed at the end of 4th week. Compared with Sh-Op group rats, the values of the area of the TAA, LA, CSA, AR, M, and M/L ratio of the aorta in $2 \mathrm{~K} 1 \mathrm{C}$ rats were markedly increased. These changes could be prevented by treatment with XJEK at all doses for 4 weeks, as well as the positive drug (Table 3, Figure 4).

\section{Effect of XJEK on endothelial dysfunction in 2K1C rats}

Aortic rings from unilateral renal clipping treated animals showed strongly reduced endothelium-dependent vasodilator responses to acetylcholine in arteries stimulated by phenylephrine compared to those in the Sh-Op (Figure 5). The aortic rings obtained from $2 \mathrm{~K} 1 \mathrm{C}$ rats treated with both XJEK and fosinopril showed a significant increase in vasodilatation induced by acetylcholine compared to the rings from the model group.

\section{Effect of XJEK on serum Ang II content}

The concentrations of Ang II measured in serum after 8 weeks are shown in Figure 6. Ang II content in $2 \mathrm{~K} 1 \mathrm{C}$ treatment is obviously increased than that in the Sh-Op group. Besides, administration of XJEK markedly reduced Ang II concentration in a dose-dependent manner, as well as the fosinopril group $(\mathrm{P}<0.01$, Figure $6-\mathrm{A})$.

\section{Effect of XJEK on serum SOD activity, MDA content and $\mathrm{NO}$ content in $2 \mathrm{~K} 1 \mathrm{C}$ rats}

Lower SOD was found in $2 \mathrm{~K} 1 \mathrm{C}$ hypertensive rats compared with Sh-Op, and XJEK treatment restored SOD activity (Figure 6-B). Serum MDA was observably increased in the $2 \mathrm{~K} 1 \mathrm{C}$ group in 4 th wk compared with Sh-Op group. Administration with XJEK at all doses for 4 weeks inhibited the increase of serum MDA markedly (Figure 6-C). Serum $\mathrm{NO}$ contents were significantly decreased in $2 \mathrm{~K} 1 \mathrm{C}$ group in comparison with Sh-Op group and XJEK administration at all doses for 4 weeks increased NO contents markedly (Figure 6-D).

\section{Discussion and conclusions}

The main findings of the present study reveal that treatment with XJEK prevents hypertension and cardiovascular remodeling in unilateral renal clipping rats, which seems to be related to the attenuation of OS. Furthermore, the results also indicate that XJEK moderate ED, confirmed by increasing serum $\mathrm{NO}$ production, which may cooperate with their beneficial cardiovascular effects. This is the first study to compare the effects of significantly different doses of XJEK on biochemical, morphological and functional alterations caused by $2 \mathrm{~K} 1 \mathrm{C}$ hypertension.

Renovascular hypertension in the $2 \mathrm{~K} 1 \mathrm{C}$ model is characterised by elevated Ang II expression resulted from

Table 3 Effect of XJEKs on aorta remodeling in $2 \mathrm{~K} 1 \mathrm{C}$ rats (mean $\pm \mathrm{SD}, \boldsymbol{n}=\mathbf{8} \sim 11$ )

\begin{tabular}{lllllllll}
\hline Group & TAA $\left(\times \mathbf{1 0}^{\mathbf{3}} \mathbf{u m}^{2}\right)$ & LA $\left(\times \mathbf{1 0}^{\mathbf{3}} \mathbf{u m}^{\mathbf{2}}\right)$ & CSA $\left(\times \mathbf{1 0}^{\mathbf{3}} \mathbf{u m}^{2}\right)$ & CSA/TAA (\%) & AR (um) & Lumen (um) & Media (um) & Media/lumen (\%) \\
\hline Sh-Op & $2671.83 \pm 108.18$ & $2354.67 \pm 99.27$ & $317.17 \pm 56.36$ & $11.86 \pm 1.99$ & $374.58 \pm 16.07$ & $339.72 \pm 18.89$ & $34.86 \pm 4.85$ & $10.33 \pm 1.90$ \\
Model & $2819.57 \pm 82.65^{* *}$ & $2454.29 \pm 71.59^{*}$ & $365.29 \pm 86.36$ & $12.92 \pm 2.81$ & $405.23 \pm 13.43^{* *}$ & $357.43 \pm 12.14^{*}$ & $47.80 \pm 5.27^{* *}$ & $13.39 \pm 1.52^{* *}$ \\
XJEK & & & & & & & & \\
$6 \mathrm{~g} / \mathrm{kg}$ & $2854.00 \pm 162.03$ & $2505.29 \pm 176.62$ & $348.71 \pm 35.81$ & $12.27 \pm 1.66$ & $408.76 \pm 20.55$ & $364.43 \pm 24.35$ & $44.32 \pm 4.79$ & $12.27 \pm 2.10$ \\
$12 \mathrm{~g} / \mathrm{kg}$ & $2764.00 \pm 185.83$ & $2411.33 \pm 250.26$ & $352.67 \pm 66.40$ & $12.90 \pm 3.13$ & $400.35 \pm 26.12$ & $354.46 \pm 29.84$ & $45.89 \pm 4.95$ & $13.06 \pm 2.31$ \\
$24 \mathrm{~g} / \mathrm{kg}$ & $2694.33 \pm 82.08^{\# \#}$ & $2379.67 \pm 65.31^{\#}$ & $314.67 \pm 45.65^{\#}$ & $11.66 \pm 1.52$ & $383.59 \pm 11.80^{\# \#}$ & $347.32 \pm 16.20$ & $36.27 \pm 11.11^{\# \#}$ & $10.54 \pm 3.54^{\#}$ \\
Fosinopril & & & & & & & & \\
$15 \mathrm{mg} / \mathrm{kg}$ & $2692.13 \pm 77.46^{\# \#}$ & $2410.13 \pm 111.76$ & $282.00 \pm 56.86^{\# \#}$ & $10.50 \pm 2.28^{\#}$ & $384.36 \pm 26.74^{\#}$ & $347.05 \pm 33.86$ & $37.30 \pm 13.02^{\#}$ & $11.11 \pm 4.93$ \\
\hline
\end{tabular}

TAA area of total aorta, $L A$ area of lumen, CSA cross-sectional area, $A R$ aorta radius. The vascular remodeling of the upper thoracic aorta exposed to $2 \mathrm{~K} 1 \mathrm{C}$ was observed at the end of $4^{\text {th }}$ week, which could be prevented by treatment with XJEK at all doses for 4 weeks, as well as the positive drug fosinopril. ${ }^{*} P<0.05$, ${ }^{* *} P<0.01$ vs Sh-Op group; ${ }^{*} P<0.05,{ }^{\# \#} P<0.01$ vs model group. 


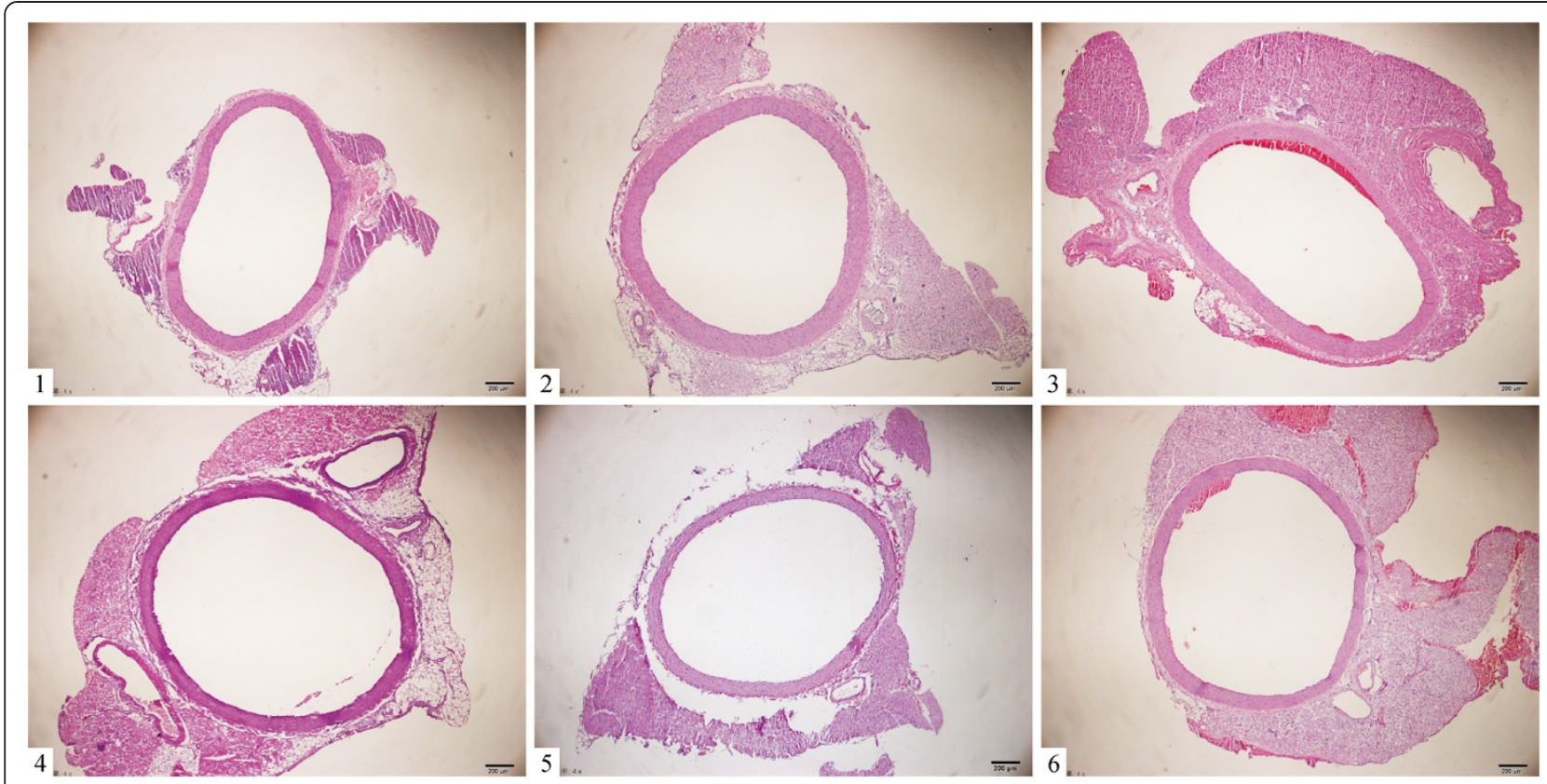

Figure 4 Representative figure of aortic remodeling in different groups. (HE staining, $\times 40$ ) Group divided ibidem.

ischemia in the clipped kidney and shear stress in the non-clipped kidney, sustained increase of blood pressure and the following cardiovascular remodeling. CR is defined as genome expression, especially the re-expression of fetal isoforms such as atrial natriuretic peptide (ANP) [17], cellular, including the enlargement of cell size and mass of individual cardiomyocytes without an increase in cell number; and interstitial fibrosis, manifested clinically as changes in the size, shape, and function of the heart after cardiac injury [18]. Various harmful sequelae of cardiovascular diseases and conditions such as coronary heart

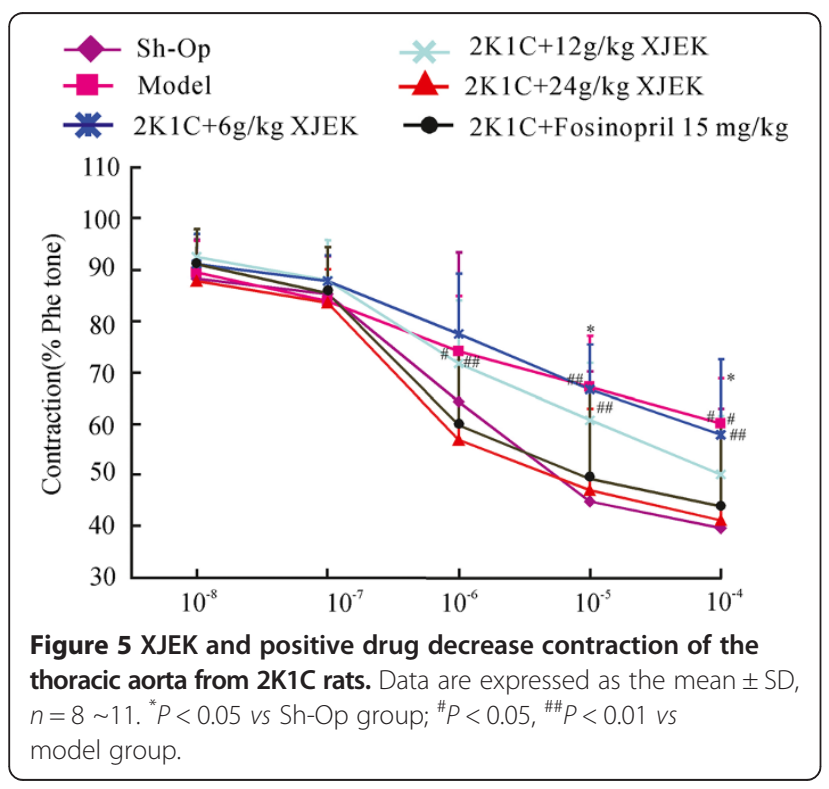

disease, stroke, congestive heart failure and sudden death are known to be aggravated by CR $[19,20]$. Apart from $\mathrm{CR}$, this experimental model is also associated with changes in the structural and mechanical properties of the arteries (named vascular remodeling, VR), including arterial wall hypertrophy and an increase in media/lumen ratio, changes in vascular wall stiffness ascribing to the up-regulation of matrix metalloproteinases (MMPs) [21] and severe renal histopathological lesions (such as glomerular hypertrophy, tubulointerstitial damage and glomerular volume) [22]. These changes increase vascular resistance to flow, further compounding the elevation in blood pressure. In accordance with these previous studies, the present study reveals that $2 \mathrm{~K} 1 \mathrm{C}$ treatment results in prominent cardiovascular remodeling, manifested as elevation in $\mathrm{HW} / \mathrm{BW}$ and CSA, and increase in collagen deposition, wall thickness, TAA, media thickness. Our present results also demonstrate that chronic oral administration with XJEK prevents hypertension and cardiovascular remodeling in this $2 \mathrm{~K} 1 \mathrm{C}$-induced hypertensive rat model.

Ang II is the primary effector molecule of the reninangiotensin system. It is primarily recognized for its role in the regulation of arterial pressure and blood volume [23]. In addition to its pressor effect, Ang II has a variety of non-hemodynamic actions. For example, Ang II-induced cell growth and fibrosis may bring about left ventricular hypertrophy and vascular remodeling. Recently, the role of OS in cardiovascular diseases has been characterized. Many of the deleterious cellular phenotypes presented in hypertrophied and failing myocardium might 

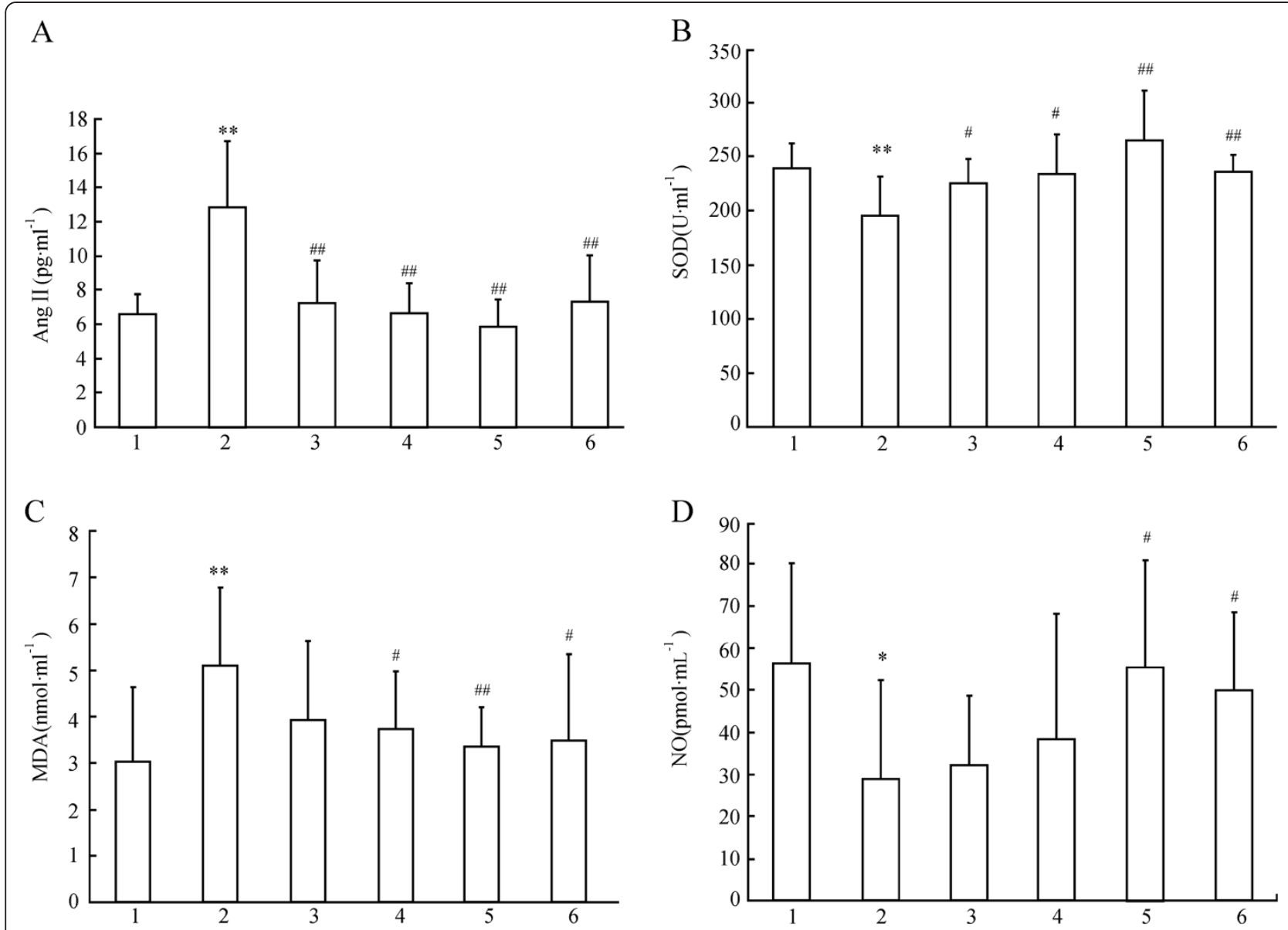

Figure 6 Effects of XJEK on serum Ang II concentrations (A), SOD content (B), MDA content (C) and NO content (D) in 2K1C rats. Group divided ibidem. Data are expressed as mean \pm SD, $n=8 \sim 11 .{ }^{*} P<0.05,{ }^{* *} P<0.01$ vs Sh-Op group; ${ }^{\#} P<0.05,{ }^{\# \#} P<0.01$ vs model group.

contribute to ROS and OS, and it is clear that NADPH oxidase-derived ROS production plays a critical role in the hypertension induced by Ang II. In a model of in vivo cardiac hypertrophy induced by short-term (7-14 day) sub-pressor infusion of Ang II [24], it has been found that increase in heart/body weight ratio, myocyte area and mRNA expression of ANF and $\beta-\mathrm{MHC}$, whilst administration of a NADPH oxidase inhibitor reduces vascular $\mathrm{O}_{2}^{-}$production and attenuates Ang II-induced increase in blood pressure [25]. This NADPH oxidase-derived ROS function as secondary messengers activating myriad redoxsensitive downstream targets, such as RAS, c-src, the MAPKs, the PI3 kinase (PI3K)/Akt pathway, NF-kB, AP-1, HIF-1 and others, the significant role of which has been confirmed in cardiovascular remodeling [26]. Furthermore, these excessively generated ROS may directly react with $\mathrm{NO}$, thereby stimulating the production of the $\mathrm{NO} /$ superoxide anion reaction product peroxynitrite $\left(\mathrm{ONOO}^{-}\right)$, accordingly, increased $\mathrm{ONOO}^{-}$ may impair the function of the endothelial NO synthase (eNOS) by reducing the bioavailability of its co-enzyme tetrahydrobiopterin $\left(\mathrm{BH}_{4}\right)$, which is required for NOS dimer formation and only if in this coupled state eNOS consumes $\mathrm{NADPH}$ and generates $\mathrm{NO}$ and $L$-citrulline from $L$-arginine and $\mathrm{O}_{2}$. The decreasing bioavailability of $\mathrm{BH}_{4}$ induces an unstable structure of eNOS, a phenomenon known as 'eNOS uncoupling' and on protein gels, it appears more as a monomer, and electrons become diverted to molecular oxygen rather than to $L$-arginine, resulting in $\mathrm{O}_{2}^{-}$formation, which thereby causes an anticardiovascular remodeling NO-producing enzyme to become a ROS-producing one, and accelerates the cardiovascular remodeling process hence [27]. Our present study reveals that blunted endothelium-dependent relaxation response to acetylcholine in noradrenaline precontracted aortic rings and decrease NO content in serum, accompanied with $\mathrm{OS}$ in this $2 \mathrm{~K} 1 \mathrm{C}$ rats hypertensive rat model. Ginseng, Astragalus mongholicus, Radix Ophiopogonis and Polygonatum odoratum are the main components of XJEK formula. It has been reported that ginsenoside exists in ginseng, and total flavonoids of Astragalus (the active component of Astragalus mongholicus Bunge) and the 
decoction of Radix Ophiopogonis exhibit a potent antioxidant activity [28-30]. Our present study demonstrates that chronic treatment with XJEK prevents ED and OS in a doses-dependent mode. In conclusion, marked OS exists in the $2 \mathrm{~K} 1 \mathrm{C}$ hypertensive rat model as described in the data, which participates in cardiovascular remodeling and endothelial dysfunction, at least in part. Chronic treatment with $\mathrm{XJEK}$ prevents these pathological changes as well as the positive drug-fosinopril. The protective effect is most likely due to the ability of XJEK to attenuate OS and/or by improving ED and increasing NO release in this $2 \mathrm{~K} 1 \mathrm{C}$ hypertensive rat model.

\section{Competing interests}

The authors have no actual or potential conflict of interest associated with this work.

\section{Authors' contributions}

GS, YTT and CHC participated in the design of the study data analyses and manuscript preparation. YTT, GK, LCZ and WXH conducted the assays and analyses. All authors read and approved the final manuscript.

\section{Acknowledgement}

This work was supported by National Natural Science Foundation of China (No 81073088) and PhD Programs Foundation of Ministry of Education of China (No 20103420120002).

\section{Author details}

'Department of Pharmacology, Key Laboratory of Antiinflammatory and Immunopharmacology of Education Ministry, Basic Medical College, Anhui Medical University, Hefei 230032, China. ${ }^{2}$ Department of Neurosurgery, Suzhou Kowloon Hospital, Shanghai Jiaotong University School of Medicine, Suzhou, Jiangsu 215021, China. ${ }^{3}$ Department of Traditional Chinese medicine, College of Pharmacy, Anhui University of Chinese Medicine, Hefei 230038, China. ${ }^{4}$ Department of General Surgery, the First Affiliated Hospital of Anhui Medical University, Hefei, Anhui 230022, China.

Received: 28 January 2013 Accepted: 5 July 2013

Published: 13 July 2013

\section{References}

1. Frohlich ED: State of the Art lecture. Risk mechanisms in hypertensive heart disease. Hypertension 1999, 34:782-789.

2. Lawes $C M$, Vander Hoorn S, Rodgers A: International Society of Hypertension, Global burden of blood-pressure-related disease, 2001. Lancet 2008, 371:1513-1518.

3. Basile DP, Donohoe DL, Phillips SA, Frisbee JC: Enhanced skeletal Muscle arteriolar reactivity to ANGIl after recovery from ischemic acute renal failure. Am J Physiol Regul Integr Comp Physiol 2005, 289:1770-1776.

4. Higashi Y, Sasaki S, Nakagawa K, Matsuura H, Oshima T, Chayama K: Endothelial function and oxidative stress in renovascular hypertension. N Engl J Med 2002, 346:1954-1962.

5. Garrido AM, Griendling KK: NADPH oxidases and angiotensin II receptor signaling. Mol Cell Endocrinol 2009, 302:148-158.

6. Romero JC, Reckelhoff JF: State-of-the-Art lecture. Role of angiotensin and oxidative stress in essential hypertension. Hypertension 1999, 34:943-949.

7. Versari D, Daghini E, Virdis A, Ghiadoni L, Taddei S: Endothelium-dependent contractions and endothelial dysfunction in human hypertension. $\mathrm{Br} J$ Pharmacol 2009, 157:527-536.

8. Toblli JE, DiGennaro F, Giani JF, Dominici FP: Nebivolol: impact on cardiac and endothelial function and clinical utility. Vasc Health Risk Manag 2012, 8:151-160.

9. Wang QM, Chen GL, Wang YJ, Wang HS, Gao MH, Gong YZ: An experimental study on inhibitory effect of xinjierkang granules on virus myocarditis. Zhongguo Zhong Yao Za Zhi 2000, 25:293-296.

10. Wang J, Cao EZ, Li LZ: Xin Ji Er Kang in coronary heart disease. Nanjing Zhong Yi Yao Da Xue Xue Bao 1998, 14:201-212.
11. Gao S, Wang XH, Huang LL, Yu T: Effects of a compound Chinese medicine Xinjierkang on isoproterenol-induced ventricular remodeling in mice. J Chin Intergr Med 2012, 10:330-336.

12. Gao S, Huang LL, Wang XH, Yu TT, Du SM, Guo YW: Effects of Xinjierkang on two kidney one clip-induced hypertension and target organ injury in rats. J Chin Med Mat 2012, 35:591-595.

13. Gao S, Long $\mathrm{CL}$, Wang RH, Wang H: K(ATP) activation prevents progression of cardiac hypertrophy to failure induced by pressure overload via protecting endothelial function. Cardiovasc Res 2009, 83:444-456.

14. Wang XH, Huang LL, Yu TT, Zhu JH, Shen B, Zhang Y, Wang HZ, Gao S: Effects of Oligomeric grape seed Proanthocyanidins on heart, Aorta, Kidney in DOCA-Salt Mice: role of oxidative stress. Phytother Res 2012. Epubmed ahead of print

15. Veltkamp R, Rajapakse N, Robins G, Puskar M, Shimizu K, Busija D: Transient focal ischemia increases endothelial nitric oxide synthase in cerebral blood vessels. Stroke 2002, 33:2704-2710.

16. Wu YB, Shi LL, Wu YJ, Xu WH, Wang L, Ren MS: Protective effect of gliclazide on diabetic peripheral neuropathy through Drp-1 mediated-oxidative stress and apoptosis. Neurosci Lett 2012, 523:45-49.

17. Bell D, Kelso EJ, Argent CC, Lee GR, Allen AR, McDermott BJ: Temporal characteristics of cardiomyocyte hypertrophy in the spontaneously hypertensive rat. Cardiovasc Pathol 2004, 13:71-78.

18. Gupta S, Das B, Sen S: Cardiac hypertrophy: mechanisms and therapeutic opportunities. Antioxid Redox Signal 2007, 9:623-652.

19. Haider AW, Larson MG, Benjamin EJ, Levy D: Increased left ventricular mass and hypertrophy are associated with increased risk for sudden death. J Am Coll Cardiol 1998, 32:1454-1459.

20. Levy D, Garrison RJ, Savage DD, Kannel WB, Castelli WP: Prognostic implications of echocardiographically determined left ventricular mass in the Framingham Heart Study. N Engl J Med 1990, 322:1561-1566.

21. Guimaraes DA, Rizzi E, Ceron CS, Oliveira AM, Oliveira DM, Castro MM, Tirapelli CR, Gerlach RF, Tanus-Santos JE: Doxycycline dose-dependently inhibits MMP-2-mediated vascular changes in 2K1C hypertension. Basic Clin Pharmacol Toxicol 2011, 108:318-325.

22. Wenzel UO, Wolf G, Jacob I, Schwegler C, Qasqas A, Amann K, Helmchen U, Stahl RA: Beneficial and adverse renal and vascular effects of the vasopeptidase inhibitor omapatrilat in renovascular hypertensive rats. Nephrol Dial Transplant 2003, 18:2005-2013.

23. Kim S, Iwao H: Molecular and cellular mechanisms of angiotensin II-mediated cardiovascular and renal diseases. Pharmacol Rev 2000, 52:11-34.

24. Bendall JK, Cave AC, Heymes C, Gall N, Shah AM: Pivotal role of a gp91 (phox)-containing NADPH oxidase in angiotensin II-induced cardiac hypertrophy in mice. Circulation 2002, 105:293-296.

25. Rey FE, Cifuentes ME, Kiarash A, Quinn MT, Pagano PJ: Novel competitive inhibitor of $\mathrm{NAD}(\mathrm{P}) \mathrm{H}$ oxidase assembly attenuates vascular $\mathrm{O}(2)(-)$ and systolic blood pressure in mice. Circ Res 2001, 89:408-414.

26. Murdoch CE, Zhang M, Cave AC, Shah AM: NADPH oxidase-dependent redox signalling in cardia hypertrophy, remodelling and failure. Cardiovasc Res 2006, 71:208-215.

27. Takimoto E, Champion HC, Li M, Ren S, Rodriguez ER, Tavazzi B, Lazzarino G, Paolocci N, Gabrielson KL, Wang Y, Kass DA: Oxidant stress from nitric oxide synthase-3 uncoupling stimulates cardiac pathologic remodeling from chronic pressure load. J Clin Invest 2005, 115:1221-1231.

28. Saw CL, Yang AY, Cheng DC, Boyanapalli SS, Su ZY, Khor TO, Gao S, Wang J, Jiang ZH, Kong AN: Pharmacodynamics of Ginsenosides: antioxidant activities, activation of Nrf2 and potential synergistic effects of combinations. Chem Res Toxicol 2012, 25:1574-1580.

29. Wang $D$, Zhuang $Y$, Tian $Y$, Thomas GN, Ying M, Tomlinson B: Study of the effects of total flavonoids of Astragalus on atherosclerosis formation and potential mechanisms. Oxid Med Cell Longev 2012. Epubmed ahead of print.

30. Wang $Y$, Bai $L, H e X$ : Scavenging action of shengmaiyin decoction on hydroxyl radical. Zhong guo Zhong Yao Za Zhi 1998, 23:45-47.

doi:10.1186/1472-6882-13-173

Cite this article as: Yu et al:: Effects of traditional Chinese medicine Xin-Ji-Er-Kang formula on $2 \mathrm{~K} 1 \mathrm{C}$ hypertensive rats: role of oxidative stress and endothelial dysfunction. BMC Complementary and Alternative Medicine 2013 13:173. 